\title{
PENGARUH LINGKUNGAN PENGAMATAN PADA KETELITIAN HORISONTAL GNSS DENGAN METODE RTK-NTRIP
}

\author{
Syafril Ramadhon \\ Pusat Pengembangan Sumber Daya Manusia Minyak dan Gas Bumi, Cepu
}

\begin{abstract}
ABSTRAK
Penelitian ini bertujuan untuk membuktikan secara empiris pengaruh lingkungan pengamatan pada ketelitian horisontal GNSS dengan metode RTK-NTRIP dengan penekanan pada berbagai kemungkinan kondisi obstruksi dan lamanya waktu untuk mencapai ketelitian $\leq 5 \mathrm{~cm}$. Penelitian dilaksanakan dengan melakukan pengukuran GNSS dengan metode RTK-NTRIP pada lokasi-lokasi yang mengakomodir berbagai kemungkinan obstruksi yang ditimbulkan oleh lingkungan pengamatan, yaitu: lokasi yang relatif bebas obstruksi, lokasi yang terdapat bangunan pada salah satu dari empat arah mata angin, lokasi pengukuran di bawah pohon, dan lokasi pengukuran yang diapit oleh dua bangunan. Analisis data dilakukan secara deskriptif dengan membandingkan ketelitian horisontal yang mampu dicapai pada setiap lokasi dan waktu untuk mencapai ketelitian tersebut. Hasil penelitian menunjukan bahwa obstruksi pada lokasi pengamatan sangat berpengaruh pada lamanya waktu untuk mencapai ketelitian $\leq 5 \mathrm{~cm}$, bahkan pada lokasi pengamatan diantara dua bangunan, ketelitian $\leq 5 \mathrm{~cm}$ tidak dapat dicapai.
\end{abstract}

Kata kunci: Lingkungan Pengamatan, GNSS, RTK-NTRIP, Ketelitian Horisontal

\begin{abstract}
TThe aim of this research is to empirically prove the influence of the observation environment on the horizontal accuracy of GNSS by the RTK-NTRIP method with an emphasis on various possible obstruction conditions and the length of time to achieve accuracy $\leq 5 \mathrm{~cm}$. The study was conducted by measuring the GNSS using the RTK-NTRIP method at locations that accommodate a variety of possible obstructions caused by the observation environment, namely: a location that is relatively obstruction-free, the location of the building in one of the four coordinate directions, the location of measurements in under the tree, and the measurement location between two buildings. Data analysis was performed descriptively by comparing horizontal accuracy which was able to be achieved at each location and time to achieve that accuracy. The results showed that obstruction at the observation environment is very influential on the length of time to reach accuracy $\leq 5 \mathrm{~cm}$, even at the observation site between two buildings, accuracy $\leq 5 \mathrm{~cm}$ cannot be achieved.
\end{abstract}

Keywords: Observation Environment, GNSS, RTK-NTRIP, Horizontal Accuracy 


\section{PENDAHULUAN}

Global Navigation Satellite Systems (GNSS) merupakan terminologi untuk semua sistem satelitnavigasi yang telah beroperasiatau masih direncanakan, yang antara lain adalah sistem satelit GPS, GLONASS, Galileo, BeiDou, IRNSS, dan QZSS (Khomsin, Anjasmara, Pratomo, \& Ristanto, 2019). Penggunaan sistem GNSS telah menyediakan informasi yang lebih presisi pada informasi waktu dan posisi di permukaan bumi, dibandingkan dengan hanya menggunakan satu sistem satelit Global Positionong Systems-GPS (Ghilani \& Wolf, 2012). Hal tersebut telah dibuktikan melalui beberapa penelitian yang disarikan oleh Khomsin dkk. (2019) sebagai berikut: (1) kombinasi sinyal GNSS antara BeiDou dan GPS menghasilkan koordinat 3-dimensi dengan tingkat akurasi dan presisi yang lebih baik; serta (2) kombinasi sinyal GPS dan GLONASS dapat meningkatkan akurasi menjadi orde-milimeter untuk baseline pendek dan orde-centimeter untuk baseline panjang.

Metode penentuan posisi menggunakan GNSS yang paling dasar adalah single point positioning yang hanya memerlukan satu receiver GNSS yang mampu menerima minimal empat sinyal satelit untuk memperoleh data koordinat 3-dimensi dari titik yang akan ditentukan posisinya (Han, Wu, \& Liu, 2012). Akan tetapi, ketelitian posisi dengan metode tersebut dipengaruhi oleh berbagai bias dan kesalahan (Abidin, 2006). Untuk mengeliminasi ataun mereduksi berbagai kesalahan dan bias tersebut, maka digunakan metode penentuan posisi secara relatif diferensial, sehingga didapatkan data koordinat yang lebih presisi (Han et al., 2012). Metode penentuan posisi secara relatif diferensial minimum dilakukan menggunakan dua receiver GNSS yang secara simultan mengamati satelit-satelit GNSS, dimana satu receiver GNSS ditempatkan pada titik ikat pemetaan yang sudah diketahui koordinatnya (based), dan receiver lainnya ditempatkan pada titik yang akan ditentukan koordinatnya (rover). Setiap data pengukuran pada base dan rover yang mengamati satelit-satelit yang sama secara simultan memiliki kesalahan dan bias yang relatif sama, sehingga apabila dilakukan proses pengurangan (differencing) tentunya kesalahan tersebut akan tereliminasi atau tereduksi yang berdampak pada semakin presisinya koordinat yang dihasilkan (Abidin, 2006).

Proses differencing pada metode penentuan secara relatif sendiri dapat dilakukan secara post-processing dan real-time (Abidin, 2006). Untuk proses secara post-processing, differencing data antara base dan rover dilakukan menggunakan perangkat lunak, sehingga koordinat yang dihasilkan pada rover didapat setelah proses pengolahan data yang umumnya dilakukan setelah kegiatan pengukuran selesai. Adapun pada proses secara real-time, data satelit pada base dikirimkan kepada rover melalui sinyal radio Very High Frequency (VHF) untuk kemudian dilakukan proses differencing data antara base dan rover di receiver GNSS, sehingga koordinat pada rover dengan kesalahan dan bias yang telah tereliminasi atau tereduksi secara real-time didapat (El Fadhila \& Khomsin, 2013). Akan tetapi dalam mengimplementasikan metode penentuan posisi secara real-time masih terdapat kendala, terutama terkait keterbatasan jangkauan sinyal radio antara base dan rover (Dammalage \& Samarakoon, 2008; Safi'i \& Aditya, 2017).

Untuk mengatasi masalah tersebut, maka pada tahun 2004, Federal Agency for Cartography and Geodesy (BKG) di Jerman mengembangkan teknologi Network Transport of RTCM via Internet Protocol (NTRIP) yang memungkinkan terjadinya koneksi data antara based dan rover melalui akses internet, 
(He, Tang, Yang, Wang, \& Liu, 2014). Pada sistem ini, jaringan kerangka dasar geodetik yang berfungsi sebagai base disebar sehingga memungkinkan rover atau pengguna dapat memanfaatkan data satelit dari base tersebut melalui akses internet. Jaringan kerangka dasar geodetik tersebut dinamakan Continuously Operating Reference Station (CORS) yang beroperasi secara penuh dan kontinyu selama 24 jam dengan mengumpulkan, merekam, dan mengirim data, sehingga pengguna cukup menggunakan satu buah receiver GNSS yang kompatibel dengan teknologi NTRIP untuk melakukan penentuan posisi secara real-time (El Fadhila \& Khomsin, 2013).

Secara teoritis, ketelitian data GNSS dengan metode Real Time Kinematik menggunakan NTRIP (RTK-NTRIP) dipengaruhi oleh beberapa faktor, yaitu: medium propagasi sinyal, jarak baseline, lingkungan pengamatan, dan konfigurasi geometris satelit (Baybura, Tiryakioğlu, Uğur, Solak, \& Şafak, 2019). Namun, berdasarkan hasil eksplorasi penulis, penelitian yang secara empiris membahas faktor-faktor yang secara teoritis mempengaruhi ketelitian data GNSS dengan metode RTK-NTRIP baru terfokus pada aspek pengaruh panjang baseline antara stasiun CORS dan rover dan aspek lingkungan pengamatan. Pada aspek pengaruh panjang baseline dari beberapa penelitian didapat temuan bahwa ketelitian data horisontal dan vertikal akan semakin menurun dengan semakin panjangnya baseline (Merry, 2007; El Fadhila \& Khomsin, 2013; Hafiz, Awaluddin, \& Yuwono, 2014; Okey, 2015). Pada aspek lingkungan pengamatan, penelitian yang dilakukan oleh Indriayati \& Nugroho (2014) menyatakan bahwa obstruksi di lingkungan pengamatan berpengaruh terhadap kualitas data GNSS dengan metode RTK-NTRIP. Akan tetapi, dalam penelitian tersebut tidak menjelaskan secara detil kondisi obstruksi dan lamanya waktu untuk mencapai ketelitian yang ingin dicapai.

Atas dasar tersebut penelitian ini bertujuan untuk membuktikan secara empiris pengaruh lingkungan pengamatan pada ketelitian data GNSS dengan metode RTK-NTRIP dengan penekanan pada berbagai kemungkinan kondisi obstruksi dan lamanya waktu untuk mencapai ketelitian horisontal $\leq 5 \mathrm{~cm}$. Penetapan ketelitian horisontal sebesar $\leq 5 \mathrm{~cm}$, adalah berdasarkan pernyataan Abidin (2006) bahwa ketelitian posisi yang diberikan oleh teknologi GPS kinematik adalah sekitar 1-5 $\mathrm{cm}$, sehingga dalam penelitian ini diasumsikan GNSS tentunya memiliki ketelitian yang lebih baik, sehingga batas ketelitian yang diharapkan melebihi $5 \mathrm{~cm}$. Penelitian ini diharapkan bermanfaat dalam hal perencanaan kegiatan survey dan pemetaan menggunakan GNSS, terutama berkaitan dengan pemilihan metode yang disesuaikan dengan karakteristik lokasi yang akan disurvey.

\section{TINJAUAN PUSTAKA}

\section{A. Teknologi NTRIP}

Teknologi NTRIP (Network Transport of RTCM via Internet Protocol) merupakan sebuah protokol standar yang didesain untuk menangani penerimaan dan pendistribusian data koreksi GNSS berupa RadioTechnical Commision for Maritime Service (RTCM) dari stasiun-stasiun referensi (CORS) kepada pengguna (rover) melalui akses internet secara real-time (Okey, 2015). RTCM sendiri merupakan format standar dari pesan-pesan koreksi, dengan RTCM Special Committee 10410.1 (RTCM SC-10410.1) versi 2.0 yang dikhususkan untuk menstandarisasi pesan koreksi real-time GNSS pada sistem NTRIP (Shkalikava, 2016).

Terdapat empat komponen utama dalam Teknologi NTRIP, yaitu: NTRIP Source, NTRIP Server, NTRIP Caster, dan NTRIP 
Client (Shkalikava, 2016). NTRIP source merupakan komponen yang berfungsi untuk menyediakan data RTCM dari stasiun CORS. Setiap NTRIP source mempunyai id unik yang dinamakan mountpoint. Data RTCM dari NTRIP Source kemudian dikirimkan kepada NTRIP Caster melalui NTRIP server melalui layanan protokol TCP/IP. NTRIP caster merupakan komponen yang bertindak sebagai sebuah server HTTP yang menerima streaming data koreksi GNSS dari satu atau lebih server NTRIP, dan juga berfungsi untuk mengirimkan data koreksi GNSS kepada satu atau lebih NTRIP client melalui internet. NTRIP client, merupakan komponen yang dapat menggunakan data RTCM dengan cara mengirimkan pesan dan kode kepada NTRIP caster dengan cara mengisi Caster Host, Caster Port, username, dan password pada mountpoint yang diinginkan. Hubungan empat komponen utama dalam teknologi NTRIP digambarkan secara skematis pada gambar 1 .

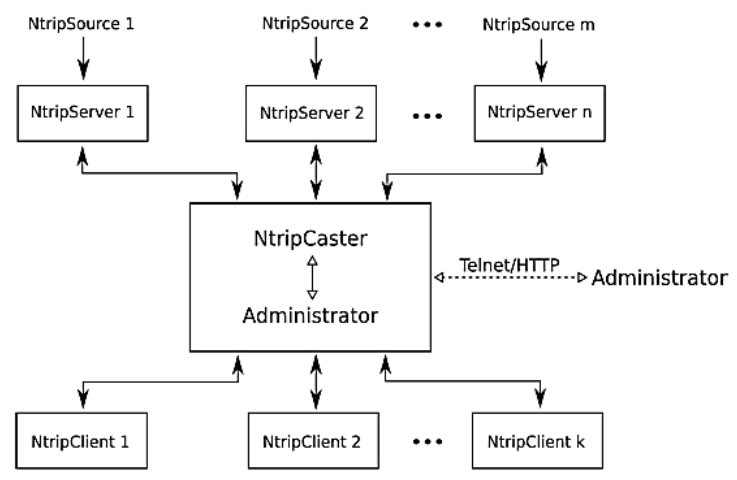

Gambar 1. Konsep Sistem NTRIP (disadur dari Shkalikava, (2016)

Metode NTRIP sudah dapat digunakan di Indonesia dengan data dari Stasiun CORS yang dapat digunakan secara gratis untuk umum. Stasiun CORS di Indonesia dikelola oleh Badan Informasi Geospasial (BIG), yang pada akhir tahun 2018 berjumlah 187 stasiun (Pusat Jaring Kontrol Geodesi dan Geodinamika, 2018). Tipe stasiun CORS di Indonesia terdiri atas dua tipe, yaitu single base station dan network base station (Setiawan, 2014). Single base station adalah system CORS yang menggunakan satu stasiun referensi untuk mengirimkan koreksi kepada rover, dengan cakupan jarak yang dapat dilayani dalam memberikan koreksi adalah dalam kisaran 10-20 km. Adapun Network Base Station adalah sistem CORS yang menggunakan lebih dari satu sistem referensi, dengan cakupan jarak yang dapat dilayani dalam memberikan koreksi adalah dalam kisaran 50-70 km.

\section{B. Pengaruh Lingkungan Pengamatan Pada Data GNSS}

Lingkungan pengamatan yang secara umum mempengaruhi kualitas data GNSS adalah terkait dengan obstruksi topografi dan efek multipath (Han et al., 2012; Kurniawan, Yuwono, \& Sabri, 2019). Obstruksi topografi merupakan kondisi dimana objek-objek topografi menghalangi visibilitas satelit dan antena GNSS (Han et al., 2012). Obstruksi topografi menyebabkan jumlah satelit yang teramati menjadi sedikit sehingga geometri satelit semakin buruk yang berdampak pada ketelitian posisi yang dihasilkan (Khomsin et al., 2019). Adapun multipath merupakan fenomena dimana sinyal satelit diterima oleh antena GNSS melalui dua atau lebih lintasan yang berbeda sebagai akibat dari pantulan objek-objek yang berada di sekitar antenna seperti gedung, danau, dan jalan aspal yang berdampak pada ukuran jarak antara satelit ke antenna yang kurang teliti (Kurniawan et al., 2019).

\section{METODE PENELITIAN}

Penelitian ini bertujuan untuk mengetahui pengaruh lingkungan pengamatan terhadap ketelitian horisontal data GNSS dengan metode RTK-NTRIP. Atas dasar tersebut, penelitian ini dilaksanakan dengan melakukan pengukuran GNSS dengan metode RTK-NTRIP pada 
lokasi-lokasi yang mengakomodir berbagai kemungkinan obstruksi yang ditimbulkan oleh lingkungan pengamatan. Lokasi-lokasi tersebut dibagi menjadi empat kriteria, yaitu: pertama, lokasi yang relatif bebas obstruksi (L1 dan L2); kedua, lokasi yang terdapat bangunan pada salah satu dari empat arah mata angin (L3, L4, L5 dan L6); ketiga, lokasi pengukuran di bawah pohon (L7); serta lokasi pengukuran yang diapit oleh dua bangunan (L8). Sketsa lokasi pengukuran diberikan pada gambar 2.

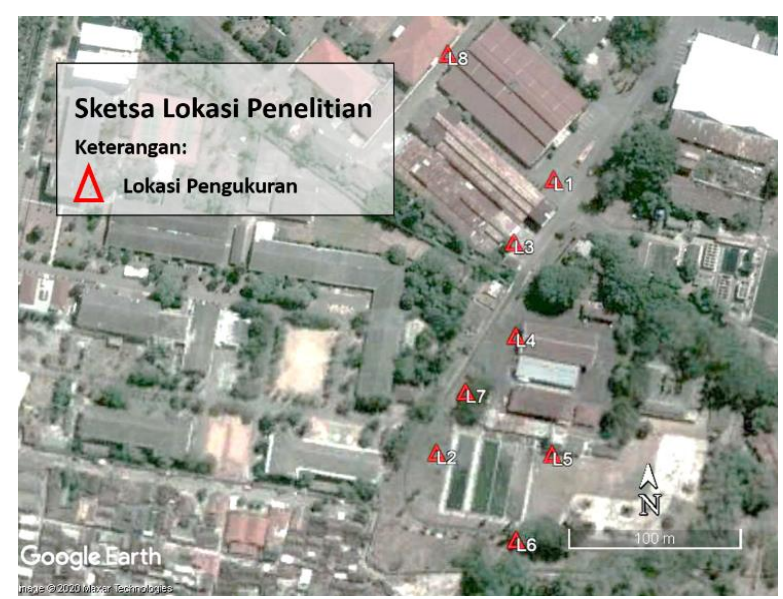

Gambar 2. Sketsa Lokasi Penelitian

Stasiun CORS yang digunakan dalam penelitian ini adalah Stasiun CORS CBLR yang berlokasi di Kabupaten Blora Jawa Tengah yang berjarak kurang lebih $28 \mathrm{~km}$ dari lokasi penelitian. Data koreksi dari stasiun CORS tersebut didapat secara gratis dengan terlebih dahulu melakukan registrasi secara daring melalui www.inacors.big.go.id untuk mendapatkan user name, password, port-number, dan ip address. Untuk memaksimalkan kualitas data GNSS, maka alat yang digunakan adalah GNSS geodetik dual frekuensi dan provider seluler yang mampu memberikan layanan 4G.

Mekanisme pengukuran yang dilakukan adalah dengan melakukan pengamatan pada setiap lokasi untuk kemudian dilakukan pencatatan terkait waktu yang diperlukan untuk mencapai ketelitian horisontal $\leq 5 \mathrm{~cm}$ yang stabil. Fokus pencatatan waktu hanya pada ketelitian horisontal didasarkan karena ketelitian vertikal umumnya 2.5 kali lebih jelek dari ketelitian horisontal (Johnson, 2004), sehingga untuk beberapa lokasi dengan obstruksi tertentu akan sulit untuk mencapai ketelitian vertikal < $5 \mathrm{~cm}$. Analisis data dilakukan secara deskriptif dengan membandingkan ketelitian horisontal yang mampu dicapai pada setiap lokasi dengan waktu untuk mencapai ketelitian tersebut.

Lokasi penelitian adalah di wilayah kantor Pusat Pengembangan Sumber Daya Manusia Minyak dan Gas Bumi (PPSDM Migas) yang berlokasi di Jl. Sorogo No.1 Kecamatan Cepu Kabupaten Blora Jawa Tengah. Adapun peralatan yang digunakan adalah: 1 set GNSS Trimble R10 Dual Frekuensi dengan provider seluler Telkomsel.

\section{HASIL PENELITIAN DAN PEMBAHASAN}

\section{A. Hasil Penelitian}

Penelitian ini bertujuan untuk mengetahui pengaruh lingkungan pengamatan dengan berbagai kemungkinan obstruksi dan lamanya waktu untuk mencapai ketelitian $\leq 5 \mathrm{~cm}$. Tabel 1 memberikan data hasil penelitian yang di dalamnya terdapat ketelitian horizontal, lamanya waktu hingga mencapai ketelitian horisontal dan vertikal yang stabil di kisaran $\leq 5 \mathrm{~cm}$, dan keterangan obstruksi di setiap lokasi penelitian. 
Tabel 1. Hasil Penelitian

\begin{tabular}{|c|c|c|c|l|}
\hline $\begin{array}{c}\text { Lokasi } \\
\text { Pengama-tan }\end{array}$ & $\begin{array}{c}\text { Ketelitian } \\
\text { Horisontal (m) }\end{array}$ & $\begin{array}{c}\text { Ketelitian } \\
\text { Vertikal (m) }\end{array}$ & Waktu & \multicolumn{1}{|c|}{ Obstruksi } \\
\hline L1 & 0.010 & 0.011 & $<1^{\prime}$ & Bebas Obstruksi \\
\hline L2 & 0.008 & 0.014 & $<1^{\prime}$ & Bebas Obstruksi \\
\hline L3 & 0.046 & 0.053 & $\pm 15^{\prime}$ & $\begin{array}{l}\text { Gedung di sisi } \\
\text { Barat }\end{array}$ \\
\hline L4 & 0.035 & 0.064 & $\pm 7^{\prime}$ & $\begin{array}{l}\text { Gedung di sisi } \\
\text { Timur }\end{array}$ \\
\hline L5 & 0.030 & 0.043 & $\pm 5^{\prime}$ & $\begin{array}{l}\text { Gedung di sisi } \\
\text { Utara }\end{array}$ \\
\hline L6 & 0.041 & 0.056 & $\pm 16^{\prime}$ & $\begin{array}{l}\text { Bangunan di sisi } \\
\text { Selatan + Pohon }\end{array}$ \\
\hline L7 & 0.028 & 0.050 & $\pm 8^{\prime}$ & Pohon \\
\hline L8 & 0.255 & 0.343 & $\pm 30^{\prime}$ & $\begin{array}{l}\text { Dua Gedung di } \\
\text { sisi timur dan } \\
\text { barat }\end{array}$ \\
\hline
\end{tabular}

Pada lokasi pengamatan yang relatif bebas obstruksi (L1 dan L2) waktu untuk mencapai ketelitian horisontal di bawah $5 \mathrm{~cm}(0.010 \mathrm{~m})$ yang stabil adalah kurang dari satu menit. Pada lokasi L3 dengan obstruksi berupa gedung di sisi barat, meskipun ketelitian horisontal mampu mencapai $<5 \mathrm{~cm}(0.046 \mathrm{~m})$, akan tetapi waktu yang dibutuhkan untuk mencapai ketelitian yang stabil tersebut adalah kurang lebih selama 15 menit. Akan tetapi, pada lokasi L4 dan L5 dengan obstruksi berupa gedung dengan ketinggian yang relatif sama dengan lokasi L3 di sisi timur dan utara, waktu yang dibutuhkan untuk mencapai ketelitian yang stabil $\leq 5 \mathrm{~cm}$ adalah kurang lebih selama 7 menit untuk L4 dan 5 menit untuk L5. Pada lokasi L6 dengan obstruksi berupa bagunan di sisi selatan ditambah dengan pohon yang mengitari lokasi pengukuran, waktu yang dibutuhkan untuk mencapai ketelitian $\leq 5 \mathrm{~cm}$ yang stabil adalah kurang lebih selama 16 menit. Untuk lokasi L7 dengan obstruksi berupa pohon waktu yang dibutuhkan untuk mencapai ketelitian $\leq 5 \mathrm{~cm}$ yang stabil adalah kurang lebih selama 8 menit. Adapun, pada lokasi L8 dengan obstruksi berupa gedung di sisi timur dan barat, ketelitian horizontal $\leq 5$ cm tidak dapat tercapai, dan hanya mampu mencapai ketelitian horisontal sebesar 0.225 $\mathrm{m}$, itu pun dengan waktu pengukuran selama kurang lebih 30 menit.

\section{A. Pembahasan}

Berdasarkan hasil penelitian didapatkan data bahwa lokasi pengamatan sangat berpengaruh pada ketelitian data GNSS menggunakan metode RTK-NTRIP. Meskipun dibeberapa lokasi yang terdapat obstruksi, ketelitian horisontal dapat mencapai $<5 \mathrm{~cm}$, akan tetapi waktu untuk mencapai ketelitian tersebut berkisar antara 5 sampai dengan 16 menit. Bahkan pada lingkungan pengamatan dengan obstruksi berupa gedung di sisi timur dan barat, ketelitian horisontal yang dapat dicapai adalah pada kisaran $22.5 \mathrm{~cm}$ dengan waktu selama kurang lebih 30 menit.

Untuk meminimalisir pengaruh panjang baseline dan juga gangguan koneksi internet, maka dalam penelitian ini digunakan alat GNSS tipe geodetik dual frekuensi dan penyedia jaringan internet yang digunakan adalah Telkomsel. Terkait dengan pengaruh panjang baseline dengan jenis alat GNSS yang digunakan, berdasarkan penelitian Cintra, Nero, \& Rodrigues (2011) menyatakan pengamatan menggunakan metode RTKNTRIP dengan alat GNSS single frekuensi gagal untuk memecahkan solusi ambiguitas 
fase pada jarak maksimum $6 \mathrm{~km}$, sedangkan alat GNSS dual frekuensi mampu memecahkan solusi ambiguitas fase hingga jarak maksimum $34 \mathrm{~km}$ dengan ketelitian horisontal $<5 \mathrm{~cm}$. Karena jarak antara stasiun CORS dengan lokasi penelitian adalah kurang lebih $28 \mathrm{~km}$, maka diasumsikan solusi ambiguitas fase terpecahkan untuk dapat mencapai ketelitian $<5 \mathrm{~cm}$. Adapun terkait dengan penyedia jaringan internet, berdasarkan penelitian Sari \& Khomsin (2014) penyedia jaringan yang terbaik terkait dengan ketelitian horisontal maupun vertikal adalah Telkomsel.

Hasil penelitian terkait lamanya waktu untuk mencapai solusi ketelitian fixed $(\leq 5 \mathrm{~cm})$ sejalan dengan penelitian yang dilakukan oleh Indriayati \& Nugroho (2014) yang menyatakan bahwa pengukuran GNSS dengan metode RTK-NTRIP sulit untuk mencapai solusi ketelitian yang fixed pada wilayah pengukuran di pemukiman padat, tertutup vegetasi, dan dilakukan di bawah SUTET. Akan tetapi menurut Sari \& Khomsin (2014) lamanya waktu mencapai nilai fixed pada metode RTK-NTRIP disebabkan karena CORS yang dijadikan sebagai base dalam keadaan kurang stabil, sehingga koneksi antara CORS dan rover seringkali terputus. Penelitian lain terkait yang dapat dijadikan sebagai penengah antara dua penelitian yang dijelaskan sebelumnya diberikan oleh Hwang, Yun, Suh, Cho, \& Lee (2012) yang menyatakan bahwa di lingkungan pengamatan yang relatif bebas obstruksi, ketelitian data GPS/GNSS menggunakan metode RTK-NTRIP mempunyai ketelitian horisontal dikisaran $2 \mathrm{~cm}$ dan ketelitian vertikal dikisaran $5 \mathrm{~cm}$ dengan waktu untuk mencapai ketelitian tersebut adalah di bawah dua detik, meskipun dalam penelitian ini tidak dijelaskan jarak antara stasiun CORS dan Rover.

Dari hasil penelitian dan penjelasan tiga penelitian tersebut ditemukan bahwa pengaruh obstruksi di lingkungan pengamatan GNSS dengan metode RTK-NTRIP memiliki pengaruh yang cukup signifikan, apalagi ditambah dengan faktor kestabilan stasiun CORS yang digunakan sebagai base. Hal tersebut juga ditunjang dengan penggunaan alat berupa GNSS geodetik dual frekuensi dan provider penyedia jaringan internet Telkomsel, sehingga pengaruh panjang baseline dan juga gangguan internet diasumsikan tidak terlalu signifikan mempengaruhi kualitas ketelitian data pengukuran. Oleh karena itu, secara umum dapat ditarik suatu bukti empiris bahwa faktor obstruksi di lingkungan pengamatan mempengaruhi ketelitian data horisontal dan lamanya waktu untuk mencapai ketelitian yang diharapkan.

\section{KESIMPULAN}

Berdasarkan hasil penelitian maupun pembahasan, dapat disimpulkan bahwa ketelitian posisi horisontal pada pengukuran GNSS dengan metode RTK-NTRIP sangat dipengaruhi oleh obstruksi di lingkungan pengamatan. Metode RTK-NTRIP sangat baik apabila dilaksanakan pada lingkungan pengamatan yang bebas obstruksi dan sebaliknya tidak optimal dilakukan di wilayah yang banyak obstruksi, baik itu berupa bangunan dan vegetasi karena memerlukan waktu yang relatif lama untuk mencapai ketelitian fixed $(\leq 5 \mathrm{~cm})$.

\section{DAFTAR PUSTAKA}

Abidin, H. (2006). Penentuan Posisi Dengan GPS dan Aplikasinya. Jakarta: Prandnya Paramitha.

Baybura, T., Tiryakioğlu, İ., Uğur, M. A., Solak, H. İ., \& Şafak, Ş. (2019). Examining the Accuracy of Network RTK and Long Base RTK Methods with Repetitive Measurements. Journal of Sensors, 2019. 
https://doi.org/10.1155/2019/3572605

Cintra, J. P., Nero, M. A., \& Rodrigues, D. (2011). GNSS/NTRIP service and technique: accuracy tests. Boletim de Ciências Geodésicas, 17(2), 257271. https://doi.org/10.1590/s198221702011000200006

Dammalage, T. L., \& Samarakoon, L. (2008). Test Results of Rtk and Real-Time Dgps Corrected Observations Based on Ntrip Protocol. The International Archives of the Photogrammetry, Remote Sensing and Spatial Information Sciences, XXXVII, 1119-1124.

El Fadhila, K., \& Khomsin. (2013). Analisis Perbandingan Ketelitian Posisi GOS CORS RTK-NTRIP dengan Metode Rapid Statik. Jurnal Teknik POMITS, $X(\mathrm{X}), 1-6$.

Ghilani, C. D., \& Wolf, P. R. (2012). Elementary Surveying: An intoduction to Geomatics (13th ed.). New Jersey: Prentice Hall.

Hafiz, E., Awaluddin, M., \& Yuwono, B. (2014). Analisis Pengaruh Panjang Baseline Terhadap Ketelitian Pengukuran Situasi dengan Menggunakan GNSS Metode RTK-NTRIP (Studi Kasus: Semarang, Kab. Kendal dan Boyolali). Jurnal Geodesi Undip, 3, 315-331.

Han, J.-Y., Wu, Y., \& Liu, R.-Y. (2012). Determining the optimal site location of GNSS base stations. Boletim de Ciências Geodésicas, 18(1), 154-169. https://doi. org/10.1590/s1982-21702012000100009

He, Z., Tang, W., Yang, X., Wang, L., \& Liu, J. (2014). Use of NTRIP for optimizing the decoding algorithm for real-time data streams. Sensors (Switzerland), 14(10), 18878-18885. https://doi.org/10.3390/ s141018878
Hwang, J., Yun, H., Suh, Y., Cho, J., \& Lee, D. (2012). Development of an RTK-GPS positioning application with an improved position error model for smartphones. Sensors (Switzerland), 12(10), 1298813001 . https://doi.org/10.3390/ s121012988

Indriayati, \& Nugroho, R. (2014). penggunaan Continuously Operating Reference System (CORS) di bidang pertanahan. Pertanahan, 4(2), 35-52.

Johnson, A. (2004). Plane and Geodetic Surveying The Management of Control Networks. London and New York: Spon Press.

Khomsin, Anjasmara, I., Pratomo, D., \& Ristanto, W. (2019). Accuracy Analysis of GNSS (GPS, GLONASS and BEIDOU) Obsevation for Positioning. In E3S Web of Conferences (Vol. 94, pp. 0-6). https://doi. org/10.1051/e3sconf/20199401019

Kurniawan, I., Yuwono, B., \& Sabri, L. (2019). Analisis pengaruh multipath dari topografi terhadap presisi pengukuran gnss dengan metode statik. Jurnal Geodesi Undip, 8(1), 10-18.

Merry, P. C. (2007). GPS NTRIP - the future of differential GPS ? PositionIT, 53-55.

Okey, O. W. (2015). Implementation of NTRIP and Management System in NIGNET Network. Universidade Da Beira Interior.

Pusat Jaring Kontrol Geodesi dan Geodinamika. (2018). Inacors BIG: Satu Referensi Pemetaan Indonesia. Cibinong: Badan Informasi Geospasial.

Safi'i, A. N., \& Aditya, A. (2017). Akurasi Pengukuran Gps Metode Rtk-Ntrip Menggunakan Ina-Cors Big. In Seminar Nasional Geomatika (Vol. 2, pp. 455-462). https://doi.org/10.24895/sng.2017.2-0.441 Sari, A., \& Khomsin. (2014). Analisa 
Perbandingan Ketelitian Penentuan

Posisi dengan GPS RTK-NTRIP dengan

Base GPS CORS BIG dari Berbagai

Macam Mobile Provider didasarkan Atas

Pergeseran Linear. GEOID, 10(1), 47-51.

Setiawan, R. (2014). Pembuatan NTRIP

Caster GNSS CORS GMU1 Menggunakan

Aplikasi Berbasis Linux. Universitas

Gadjah Mada.

Shkalikava, A. (2016). Transmission of

Position Information Via the Data Network.

Katedra Telekomunikační Techniky. 